\title{
Long-term risk of mortality after acute kidney injury in patients with sepsis: a contemporary analysis
}

\author{
José António Lopes*1, Paulo Fernandes'1, Sofia Jorge1 , Cristina Resina1', Carla Santos², Álvaro Pereira22, José Neves², \\ Francisco Antunes² and António Gomes da Costa'
}

\begin{abstract}
Background: Acute kidney injury (AKI) is associated with increased short-term mortality of septic patients; however, the exact influence of AKI on long-term mortality in such patients has not yet been determined.

Methods: We retrospectively evaluated the impact of AKI, defined by the "Risk, Injury, Failure, Loss of kidney function, End-stage kidney disease" (RIFLE) classification based on creatinine criteria, on 2-year mortality in a cohort of 234 hospital surviving septic patients who had been hospitalized at the Infectious Disease Intensive Care Unit of our Hospital.

Results: Mean-follow-up was $21 \pm 6.4$ months. During this period, 32 patients (13.7\%) died. At 6 months, 1 and 2 years of follow-up, the cumulative probability of death of patients with previous AKI was 8.3, 16.9 and $34.2 \%$, respectively, as compared with 2.2, 6 and 8.9\% in patients without previous AKI (log-rank, P < 0.0001). In the univariate analysis, age (hazard ratio 1.4, 95\% Cl 1.2-1.7, $\mathrm{P}<0.0001$ ), as well as pre-existing cardiovascular disease (hazard ratio 3.6, 95\% Cl 1.49.4, $\mathrm{P}=0.009$ ), illness severity as evaluated by nonrenal APACHE II (hazard ratio 1.3, 95\% Cl 1.1-1.6, P = 0.002), and previous AKI (hazard ratio 4.2, 95\% Cl 2.1-8.5, $\mathrm{P}<0.0001$ ) were associated with increased 2-year mortality, while gender, race, pre-existing hypertension, cirrhosis, HIV infection, neoplasm, and baseline glomerular filtration rate did not. In the multivariate analysis, however, only previous AKI (hazard ratio 3.2, 95\% Cl 1.6-6.5, P = 0.001) and age (hazard ratio 1.4, $95 \% \mathrm{Cl} 1.2-1.6, \mathrm{P}<0.0001)$ emerged as independent predictors of 2-year mortality.
\end{abstract}

Conclusions: Acute kidney injury had a negative impact on long-term mortality of patients with sepsis.

\section{Background}

Acute kidney injury (AKI) is a common complication among hospitalized patients, particularly in the Intensive Care Unit (ICU) setting, and it portends an ominous outcome. In fact, the incidence of AKI in critically ill patients varies from 35 to $70 \%$, and it is associated with increased in-hospital mortality (10 to $60 \%$ ) [1-4].

Although AKI is a common complication in the hospital and has an immediate impact on morbidity, mortality, and resource utilization, its detrimental effect appears to persist also after recovery, since AKI has shown to increase long-term mortality [5-7]. Understanding the

\footnotetext{
* Correspondence: jalopes93@hotmail.com

1 Department of Nephrology and Renal Transplantation, Hospital de Santa Maria, Centro Hospitalar Lisboa Norte, EPE, Av. Prof. Egas Moniz, Lisboa, 1649035, Portugal

Full list of author information is available at the end of the article
}

impact of AKI on long-term outcomes will have a marked impact on treatment and risk stratification during hospitalization and will assist with guiding follow-up care after discharge.

Sepsis is a well-known risk factor for the development of AKI and nearly half of all patients with AKI have sepsis $[8,9]$. Furthermore, AKI is associated with increased short-term mortality among septic patients [8-14]. Despite the detrimental effect of AKI on short-term outcome, to our knowledge, there is no study evaluating the influence of AKI on long-term mortality of hospital surviving septic patients.

In the present study, we sought to evaluate the impact of AKI on long-term mortality in a cohort of patients with sepsis. 


\section{Methods}

This is a retrospective study that evaluated the influence of AKI during previous ICU admission on long-term mortality of hospital surviving septic patients admitted to the Infectious Disease Intensive Care Unit of our hospital between July 2002 and June 2007. This unit is the reference medical infectious disease unit for adult patients with infectious diseases who need intensive care, providing medical assistance to an area (Lisbon to south of Portugal) with almost 3000000 inhabitants.

Since this was a retrospective and observational study that did not evaluate a specific therapeutic or prophylactic intervention the institutional ethical approval was not required according to our institution's guidelines.

\section{Selection criteria, population and study periods}

Between July 2002 and June 2007, 454 patients with sepsis were admitted to the unit; 28 of them were chronic kidney disease patients on dialysis and were not included in this study. None of the patients had received a renal transplant. From the 426 remaining patients (mean age: 53.3 years, 281 male, 379 Caucasian, mean APACHE II score: 21.3) (Table 1), 122 of them died within hospitalization and, therefore, 304 patients were discharged alive from the hospital (Table 2 and Table 3). Mortality was assessed at 2-years of follow-up. For those patients who were followed-up at the hospital with a documented medical visit at or after 2 years after hospital discharge, and for those patients who died at the hospital during a subsequent hospitalization after hospital discharge, longterm outcome was assessed based on hospital records. On the other hand, for those patients who were not followed-up at the hospital, the long-term outcome was assessed by phone call to patients or their family by using contact details provided on hospital database. We could not analyze the long-term outcome of 70 patients who were lost to follow-up. Therefore, in this study, we focused on 234 patients with sepsis, and analyzed their mortality at 2 years of follow-up as a cohort.

\section{Definitions}

Acute kidney injury was defined and categorized according to "Risk Injury Failure Loss of kidney function Endstage kidney disease" (RIFLE) classification, based on creatinine criteria [15]. Acute kidney injury was defined as an increase of baseline serum creatinine $\times 1.5$, and in patients with baseline serum creatinine $>4 \mathrm{mg} / \mathrm{dl}$ it was also considered if there was an acute rise in serum creatinine of at least $0.5 \mathrm{mg} / \mathrm{dl}$; Class $\mathrm{R}$ (Risk) was considered if there was an increase of baseline serum creatinine $\times 1.5$; class I (Injury) was considered if there was an increase of baseline serum creatinine $\times 2$; and Class F (Failure) was considered if there was an increase of baseline serum creatinine $\times 3$, or in patients with baseline serum creatinine $>4 \mathrm{mg} / \mathrm{dl}$ if there was an acute rise in serum creatinine of at least $0.5 \mathrm{mg} / \mathrm{dl}$. When pre-admission serum creatinine was available it was considered the baseline serum creatinine, and when it was unavailable baseline serum creatinine was estimated by the Modification of Diet in Renal Disease equation [16], as recommended (assuming a lower limit of the normal baseline glomerular filtration rate of $75 \mathrm{ml} / \mathrm{min} / 1.73 \mathrm{~m}^{2}$ ) and previously applied $[1,15]$. In this unit, serum creatinine is determined at least once a day.

Sepsis was classified in accordance with the American College of Chest Physicians and the Society of Critical Care Medicine consensus [17] and Acute Physiology and Chronic Health Evaluation, version II (APACHE II) score was used to evaluate illness severity, and was calculated based on the worst variables recorded during the first 24 hours of ICU admission [18].

Complete renal function recovery was considered if the serum creatinine at hospital discharge with reference to baseline serum creatinine was lower than $\times 1.5$, and in patients with baseline serum creatinine $>4 \mathrm{mg} / \mathrm{dl}$ complete renal function recovery was also considered if serum creatinine at hospital discharge was also lower than $0.5 \mathrm{mg} / \mathrm{dl}$ with reference to baseline serum creatinine.

\section{Variables}

Variables such as age, gender, race, comorbidity (diabetes mellitus, hypertension, cardiovascular disease which included chronic heart failure and coronary artery disease, cirrhosis, human immunodeficiency virus infection, and neoplasm), APACHE II score, need for mechanical ventilation, vasopressors use, daily serum creatinine as well as renal replacement therapy were collected from the unit database and patient medical charts.

\section{Statistical analysis}

Continuous variables are expressed as mean (standard deviation) and categorical variables as percentage of number of cases. Comparisons between patients with and without AKI were performed using the Student's t-test and the $\chi^{2}$-test, respectively, for continuous and categorical variables.

Only the first ICU presentation was analyzed for patients with multiple ICU admissions. Cumulative mortality curves were determined by the Kaplan-Meier method, and log-rank test was employed to analyze statistically significant differences between curves. Cox regression method was used to determine independent predictors of mortality. Risk factors were assessed with univariate analysis, and variables that were statistically significant $(P<0.05)$ in the univariate analysis were included in the multivariate analysis by applying a multiple forward stepwise Cox regression. The nonrenal APACHE II score was chosen as a covariate to control for multicollinearity between the AKI and scoring system that includes points for kidney insufficiency such as the 
Table 1: Baseline characteristics of the overall cohort of septic patients.

\begin{tabular}{|c|c|c|c|}
\hline Variable & Without AKI1 $(n=288)$ & With AKI ( $=138)$ & $P$ \\
\hline Mean age (years) & $50.7(18.3)$ & $58.8(16.4)$ & $<0.0001$ \\
\hline Male (\%) & 62.8 & 72.5 & 0.064 \\
\hline Caucasian (\%) & 90.6 & 85.5 & 0.158 \\
\hline $\mathrm{DM}^{2}(\%)$ & 14.6 & 16.7 & 0.678 \\
\hline Hypertension (\%) & 20.5 & 23.9 & 0.497 \\
\hline $\mathrm{CVD}^{3}(\%)$ & 6.6 & 20.3 & $<0.0001$ \\
\hline Cirrhosis (\%) & 11.8 & 10.1 & 0.731 \\
\hline HIV infection ${ }^{4}(\%)$ & 16.3 & 17.4 & 0.890 \\
\hline Neoplasm (\%) & 6.2 & 11.6 & 0.087 \\
\hline APACHE II score 5 & $18.3(8)$ & $27.5(8.6)$ & $<0.0001$ \\
\hline Nonrenal APACHE II score ${ }^{6}$ & $17.7(7.8)$ & $23.9(8.6)$ & $<0.0001$ \\
\hline Baseline $\mathrm{SCr}(\mathrm{mg} / \mathrm{dL})^{7}$ & $0.8(0.2)$ & $1(0.5)$ & $<0.0001$ \\
\hline Septic shock (\%) & 22.6 & 60.1 & $<0.0001$ \\
\hline MV8 (\%) & 39.2 & 59.4 & $<0.0001$ \\
\hline Length of hospital stay (days) & $10.7(12.5)$ & $12(13.6)$ & 0.328 \\
\hline In-hospital mortality (\%) & 15.6 & 55.8 & $<0.0001$ \\
\hline
\end{tabular}

${ }^{1} \mathrm{AKI}$-acute kidney injury. ${ }^{2} \mathrm{DM}$-diabetes mellitus. ${ }^{3 \mathrm{CVD}}$-cardiovascular disease includes chronic heart failure and coronary artery disease. ${ }^{4} \mathrm{HIV}$ infection-human immunodeficiency virus infection. ${ }^{\mathrm{A}} \mathrm{APCHE}$ II score-acute physiology and chronic health evaluation, version II score. ${ }^{6}$ Nonrenal APACHE II score-acute physiology and chronic health evaluation, version II score not including points for kidney insufficiency.

${ }^{7}$ Baseline SCr-baseline serum creatinine. ${ }^{8} \mathrm{MV}$-need for mechanical ventilation.

APACHE II score. Data are presented as unadjusted and adjusted hazard ratios (HR) with $95 \%$ confidence intervals (CI). A two-tailed $P$ value less than 0.05 was considered significant.

Analysis was performed with the statistical software package SPSS 16.0 for Windows.

\section{Results}

\section{Acute kidney injury}

Baseline serum creatinine was available in 293 patients $(68.8 \%)$, and in the remaining cases $(\mathrm{n}=133 ; 31.2 \%)$ it was estimated by the Modification of Diet in Renal Disease equation. Acute kidney injury occurred in 138 patients (32.4\%), as follows: 26 patients (6.1\%) were on class $\mathrm{R}, 34$ patients $(8 \%)$ were on class I, and 78 patients (18.3\%) were on class F. Mean time to AKI development was 2.9 (4.7) days (1-19 days). As expected, patients with AKI were older, were more likely to have pre-existing cardiovascular disease, and had more severe disease as evaluated by total APACHE II score and nonrenal APACHE II score. Furthermore, baseline creatinine values were higher among patients with AKI, and septic shock and 
Table 2: Baseline characteristics of the hospital surviving septic patients.

\begin{tabular}{|c|c|c|c|}
\hline Variable & Without AKI1 (n = 243) & With AKI $(n=61)$ & $P$ \\
\hline Mean age (years) & $50.2(18.2)$ & $58.8(16.3)$ & 0.001 \\
\hline Male (\%) & 60.5 & 77 & 0.024 \\
\hline Caucasian (\%) & 90.5 & 83.6 & 0.185 \\
\hline $\mathrm{DM}^{2}(\%)$ & 15.2 & 22.9 & 0.211 \\
\hline Hypertension (\%) & 21.8 & 32.8 & 0.104 \\
\hline $\mathrm{CVD}^{3}(\%)$ & 4.1 & 13.1 & 0.018 \\
\hline Cirrhosis (\%) & 11.1 & 9.8 & 0.955 \\
\hline HIV infection ${ }^{4}(\%)$ & 12.3 & 13.1 & 0.957 \\
\hline Neoplasm (\%) & 5.3 & 13.1 & 0.063 \\
\hline APACHE II score 5 & $16.9(7.5)$ & $24.2(7.4)$ & $<0.0001$ \\
\hline Nonrenal APACHE II score ${ }^{6}$ & $16.3(7.2)$ & $20.5(7.5)$ & $<0.0001$ \\
\hline Baseline $\mathrm{SCr}(\mathrm{mg} / \mathrm{dL})^{7}$ & $0.8(0.2)$ & $1.1(0.4)$ & $<0.0001$ \\
\hline Septic shock (\%) & 18.1 & 55.7 & $<0.0001$ \\
\hline MV8 (\%) & 32.5 & 47.5 & 0.041 \\
\hline Length of hospital stay (days) & $10.7(13)$ & $12.8(9.2)$ & 0.233 \\
\hline
\end{tabular}

need for mechanical ventilation were more frequent in such patients (Table 1 and Table 2). Forty-one AKI patients $(29.7 \%)$ did undergo renal replacement therapy (continuous venovenous hemodiafiltration in 23 patients, intermittent hemodialysis in 13 patients, and 5 patients were treated with both modalities). Patients with AKI had a greater risk for death within hospitalization (Table 1). Regarding hospital survivors lost to follow-up and with known follow-up it should be mentioned that they were similar in terms of age, gender, race, medical history, illness severity, baseline renal function, proportion of patients with AKI, proportion of AKI patients in the different RIFLE categories or undergoing renal replacement therapy, percentage of patients with septic shock or need for mechanical ventilation, and length of hospitalization (Table 3). The characteristics of the surviving and non surviving patients with AKI during ICU admission are described in Table 4.

\section{Long-term outcome}

In this study, we focused on 234 patients [mean age: 51.2 (18.2) years, 149 male, 210 Caucasian, mean APACHE II score: 18.3 (8.2)] with sepsis, and analyzed their mortality at 2 years of follow-up as a cohort. Mean-follow-up was 21 (6.4) months. During this period, 32 patients (13.7\%) died. The probability of death significantly differed among patients with AKI and without AKI during previ- 
Table 3: Baseline characteristics of the hospital surviving septic patients with known or unknown follow-up.

\begin{tabular}{|c|c|c|c|}
\hline Variable & Known follow-up ( $n=234$ ) & Unknown follow-up $(n=70)$ & $P$ \\
\hline Mean age (years) & $51.2(18.2)$ & $54.2(17.9)$ & 0.234 \\
\hline Male (\%) & 63.7 & 64.3 & 0.961 \\
\hline Caucasian (\%) & 89.7 & 87.1 & 0.693 \\
\hline $\mathrm{DM}^{1}(\%)$ & 15.8 & 20 & 0.522 \\
\hline Hypertension (\%) & 24.3 & 22.9 & 0.921 \\
\hline$C D^{2}(\%)$ & 6 & 5.7 & 0.838 \\
\hline Cirrhosis (\%) & 10.7 & 11.4 & 0.258 \\
\hline HIV infection 3 (\%) & 13.7 & 8.6 & 0.354 \\
\hline Neoplasm (\%) & 1 & 0 & 0.371 \\
\hline APACHE II score 4 & $18.3(8.2)$ & $18.7(7.2)$ & 0.751 \\
\hline Nonrenal APACHE II score 5 & $17(7.6)$ & $17.5(6.9)$ & 0.644 \\
\hline Baseline $\mathrm{SCr}(\mathrm{mg} / \mathrm{dL})^{6}$ & $0.8(0.3)$ & $0.8(0.3)$ & 0.922 \\
\hline Septic shock (\%) & 24.8 & 28.6 & 0.631 \\
\hline MV7 (\%) & 35 & 37.1 & 0.857 \\
\hline $\operatorname{AKI}^{8}(\%)$ & 20.5 & 18.6 & 0.853 \\
\hline Class R (\%) & 5.5 & 1.4 & 0.270 \\
\hline Class I (\%) & 6.8 & 6 & 0.410 \\
\hline Class F (\%) & 8.9 & 8.6 & 0.873 \\
\hline $\operatorname{RRT}^{9}(\%)$ & 29.2 & 15.4 & 0.518 \\
\hline Complete RFR ${ }^{10}(\%)$ & 87.5 & 100 & 0.414 \\
\hline Length of hospital stay (days) & $10.9(11.2)$ & $11.8(15.7)$ & 0.589 \\
\hline
\end{tabular}


ous ICU admission (Figure 1). At 6 months, 1 and 2 years of follow-up, the cumulative probability of death of patients with AKI was 8.3, 16.9 and $34.2 \%$, respectively, as compared with 2.2, 6 and $8.9 \%$ in patients without AKI (log-rank, $P<0.0001$ ) (Figure 1 ). When we analyzed 2year mortality in the different RIFLE categories, however, we did not find any statistically significant difference (class R, 7.7\%; class I, 50\%; class F, 38.1\%; $P=0.055$ ). In the univariate analysis, age (HR 1.4, 95\% CI 1.2-1.7, $P<$ $0.0001)$, as well as preexisting cardiovascular disease (HR 3.6, 95\% CI 1.4-9.4, $P=0.009$ ), illness severity as evaluated by nonrenal APACHE II (HR 1.3, 95\% CI 1.1-1.6, $P=$ 0.002 ), and AKI during previous ICU admission (HR 4.2,
95\% CI 2.1-8.5, $P<0.0001)$ were associated with increased 2-year mortality, while gender, race, pre-existing hypertension, cirrhosis, HIV infection, neoplasm, and baseline glomerular filtration rate did not. In the multivariate analysis, however, only AKI during previous ICU admission (AHR 3.2, 95\% CI 1.6-6.5, P = 0.001) and age (AHR 1.4, 95\% CI 1.2-1.6, P < 0.0001) emerged as independent predictors of 2-year mortality (Table 5).

Of interest, 2-year mortality did not significantly differ between AKI patients who completely recovered renal function $(\mathrm{n}=14,33.3 \%)$ and those who did not $(\mathrm{n}=2$, $33.3 \%)$.

Table 4: Baseline characteristics of hospital surviving and non surviving patients with acute kidney injury during Intensive Care Unit admission.

\begin{tabular}{|c|c|c|c|}
\hline Variable & Non survivors $(n=77)$ & Survivors $(n=61)$ & $P$ \\
\hline Mean age (years) & $58.8(16.6)$ & $58.8(16.3)$ & 0.991 \\
\hline Male (\%) & 68.8 & 77 & 0.378 \\
\hline Caucasian (\%) & 87 & 83.6 & 0.748 \\
\hline $\mathrm{DM}^{1}(\%)$ & 11.7 & 22.9 & 0.125 \\
\hline Hypertension (\%) & 16.9 & 32.8 & 0.048 \\
\hline $\mathrm{CVD}^{2}(\%)$ & 25.9 & 13.1 & 0.098 \\
\hline Cirrhosis (\%) & 10.4 & 9.8 & 0.885 \\
\hline HIV infection ${ }^{3}(\%)$ & 20.8 & 13.1 & 0.340 \\
\hline Neoplasm (\%) & 10.4 & 13.1 & 0.819 \\
\hline APACHE II score 4 & $30(8.6)$ & $24.2(7.4)$ & $<0.0001$ \\
\hline Nonrenal APACHE II score 5 & $26.7(8.5)$ & $20.5(7.5)$ & $<0.0001$ \\
\hline Baseline $\mathrm{SCr}(\mathrm{mg} / \mathrm{dL})^{6}$ & $1(0.5)$ & $1(0.4)$ & 0.379 \\
\hline Septic shock (\%) & 63.6 & 55.7 & 0.444 \\
\hline MV7 (\%) & 68.8 & 47.5 & 0.019 \\
\hline $\mathrm{RRT}^{8}(\%)$ & 32.5 & 26.2 & 0.543 \\
\hline
\end{tabular}

${ }^{1}$ DM-diabetes mellitus. ${ }^{2} \mathrm{CVD}$-cardiovascular disease includes chronic heart failure and coronary artery disease. ${ }^{3} \mathrm{HIV}$ infection-human immunodeficiency virus infection. ${ }^{4} \mathrm{APACHE}$ II score-acute physiology and chronic health evaluation, version II score. ${ }^{5}$ Nonrenal APACHE II score-acute physiology and chronic health evaluation, version II score not including points for kidney insufficiency. ${ }^{6}$ Baseline $\mathrm{SCr}$-baseline serum creatinine. ${ }^{7} \mathrm{MV}$-need for mechanical ventilation. ${ }^{8} \mathrm{RRT}$-need for renal replacement therapy. 


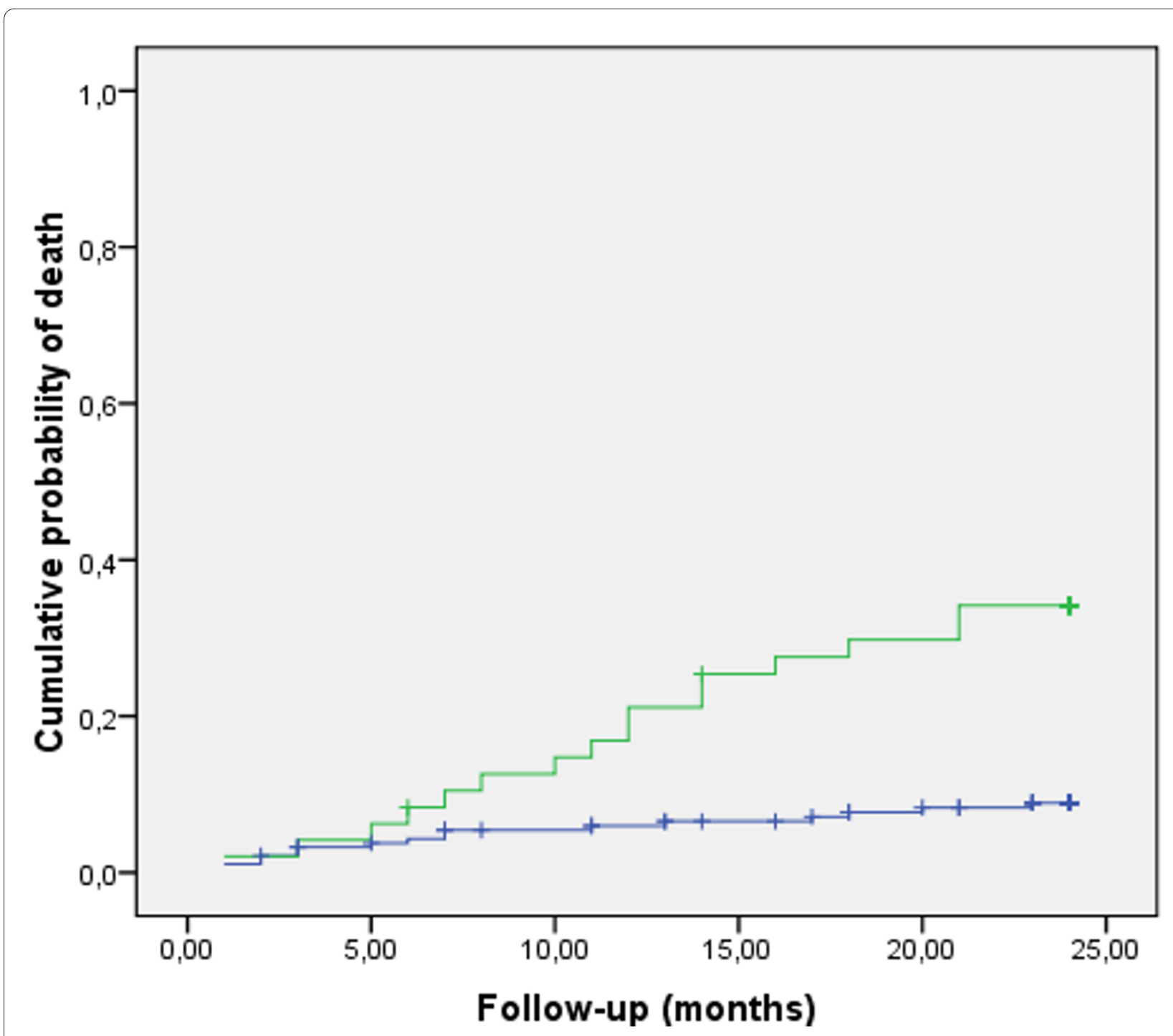

Figure 1 Cumulative probability of death. Cumulative probability of death in patients with (green line) and without (blue line) acute kidney injury (AKI) during previous Intensive Care Unit admission; log-rank test, $P<0.0001$.

\section{Discussion}

It has been shown that patients who survive AKI have a greater rate of long-term mortality and other adverse outcomes than patients who survive hospitalization without AKI, in varied settings, such as community/hospitalized patients, hospitalized patients, ICU patients, cardiac surgery, patients undergoing aortic stent placement or percutaneous coronary intervention, liver transplant and lung transplant [19].

Sepsis is a well-known risk factor for the development of AKI and nearly half of all patients with AKI have sepsis $[8,9]$. Furthermore, AKI is associated with short-term mortality among septic patients [8-14]. Despite the detrimental effect of AKI on short-term outcome, to our knowledge, the influence of AKI on long-term mortality of septic patients has not yet been assessed.

We conducted a retrospective study of a cohort of 234 hospital surviving septic patients, in order to determine the impact of AKI during ICU admission on 2-year mortality. We found that AKI had a negative impact on 2-year mortality of patients with sepsis. As compared with patients without acute renal impairment, patients with AKI had an increased probability of death of $25.3 \%$, which corresponded to a 3.2-fold risk of death. These findings expand on results from previous studies that showed the increased risk of short-term death associated with AKI in septic patients [8-14].

The mechanism by which AKI contributes to decreased long-term survival is not completely understood. After an 
Table 5: Univariate and multivariate Cox regression analysis to determine predictors of 2-year mortality.

\begin{tabular}{|c|c|c|c|c|}
\hline Variable & Unadjusted HR1 (95\% Cl3) & $P$ & AHR2 (95\% Cl3) & $P$ \\
\hline Age (per 10 years) & $1.4(1.2-1.7)$ & $<0.0001$ & $1.4(1.2-1.6)$ & $<0.0001$ \\
\hline Gender (male) & $1.1(0.5-2.3)$ & 0.752 & & \\
\hline Race (Caucasian) & $3.8(0.5-27.6)$ & 0.192 & & \\
\hline Diabetes mellitus & $2.1(0.9-4.6)$ & 0.06 & & \\
\hline Hypertension & $1.7(0.8-3.4)$ & 0.177 & & \\
\hline $\mathrm{CVD}^{4}$ & $3.6(1.4-9.4)$ & 0.009 & & \\
\hline Cirrhosis & $0.9(0.3-2.8)$ & 0.813 & & \\
\hline HIV infection 5 & $1.9(0.9-4.6)$ & 0.107 & & \\
\hline Neoplasm (\%) & $2.5(0.9-7.1)$ & 0.088 & & \\
\hline Baseline GFR ${ }^{6}$ (per $\left.10 \mathrm{ml} / \mathrm{min} / 1.73 \mathrm{~m} 2\right)$ & $1.1(0.9-1.3)$ & 0.063 & & \\
\hline Nonrenal APACHE II7(per 5 points) & $1.3(1.1-1.6)$ & 0.002 & & \\
\hline $\mathrm{AKI} \mathrm{I}^{8}$ & $4.2(2.1-8.5)$ & $<0.0001$ & $3.2(1.6-6.5)$ & 0.001 \\
\hline
\end{tabular}

episode of AKI, it is likely that there is failure to resolve renal structure and function adequately [20-22]. Acute kidney injury itself may increase the risk of subsequent events and decrease kidney reserve leading to an increased risk of chronic kidney disease. In fact, despite we do not have serial values of blood pressure, serum creatinine and proteinuria, it has been shown that chronic kidney disease with subsequent hypertension, proteinuria and increased cardiovascular disease has been appointed as a possible cause of poor long-term outcome among AKI patients [23]. Moreover, volume overload, coagulation abnormalities, an increased incidence of sepsis with multi-organ failure, and cytokine or immune-mediated major organ dysfunction are other possible explanations for poor survival among AKI patients [24,25].

In the present study, mortality did not differ among AKI patients with and without complete renal function recovery. These results should be interpreted with extreme caution, since the number of patients may be insufficient to detect a difference on outcome. However, the similar outcome between AKI patients who did or not recover renal function could also be explained by the permanent injury to other vital organs caused by AKI, thus affecting future survival, despite the reversible nature of clinical AKI in which serum creatinine level returns to baseline after the episode [24-26]. Therefore, our results could also suggest that despite patients with septic AKI are prone to recover renal function $[9,14]$, they should be closely monitored after discharge.

Our study has several limitations. First, the single-centre nature of the study largely limits its generalizability, and its retrospective design with a relatively small cohort of patients did not allow the evaluation of other confounders with prognostic importance. Second, baseline serum creatinine was available only in $68.8 \%$ of patients, while in the remaining cases $(31.2 \%)$ it was estimated by the Modification of Diet in Renal Disease equation, as it has been recommended and previously applied $[1,15]$. Regarding this, it should be stressed that the use of Modification of Diet in Renal Disease equation to estimate 
baseline serum creatinine, despite performing reasonable well when basal glomerular filtration rate is normal or near normal, could overestimate the incidence of AKI in chronic kidney disease patients [27]. Third, the evolution for chronic kidney disease and end-stage renal disease after AKI, as well as the causes of death were unattainable. Fourth, outcome data were available only in $77 \%$ of patients. Regarding this issue, it is important to mention that hospital survivors lost to follow-up and with known follow-up were similar in terms of age, gender, race, medical history, illness severity, baseline renal function, proportion of patients with AKI, proportion of AKI patients in the different RIFLE categories or undergoing renal replacement therapy, percentage of patients with septic shock or need for mechanical ventilation, and length of hospitalization. Taking into consideration the similar characteristics of hospital survivors lost to follow-up and with known follow-up, we think that it is not expectable that substantially different results would be achieved if the outcome data of all surviving patients was available. In fact, our results are in line with those focusing on the effect of AKI on long-term outcome in other settings [19], and likely, AKI can also exert a negative influence on long-term outcome of patients with sepsis. Finally, the number of patients in the different AKI categories was too small to determine the role of severity of AKI on long-term outcome.

Despite the aforementioned constraints, our study has the main virtue of being, to our knowledge, the first study reporting the negative impact of AKI on long-term mortality of patients with sepsis, a specific setting where AKI is pathophysiological and clinically distinct from AKI of other etiologies $[9,28]$. The appropriate management of the patients with sepsis through early goal-directed resuscitation, early administration of broad-spectrum antibiotic therapy, therapy with vasopressor agents (when fluid challenge fails to restore adequate blood pressure and organ perfusion), use of recombinant activated protein $C$ (in patients with severe sepsis and high risk for death), use of low-tidal volume ventilation and blood glucose control is essential to prevent or limit AKI severity and, as such, could improve the long-term outcome of septic patients after hospital discharge [29].

\section{Conclusions}

Our results suggest that AKI negatively influences longterm mortality of patients with sepsis. Despite septic patients who develop AKI and survive their acute episode have greater likelihood for renal function recovery the negative impact of AKI on long-term mortality deserves an additional effort to closely monitor them after hospital discharge.

\section{Abbreviations}

AHR: adjusted hazard ratios; AKI: acute kidney injury; ANOVA: one-way analysis of variance; APACHE II score: acute physiology and chronic health evaluation, version II score; Cl: confidence intervals; CVD: cardiovascular disease; DM: diabetes mellitus; GFR: glomerular filtration rate; HIV: human immunodeficiency virus; HR: hazard ratios; ICU: intensive care unit; MV: need for mechanical ventilation; RIFLE: Risk Injury Failure Loss of kidney function End-stage kidney disease; RRT: need for renal replacement therapy; SCr: serum creatinine.

\section{Competing interests}

The authors declare that they have no competing interests.

\section{Authors' contributions}

$J A L$ participated in the conception of the study, analysis and interpretation of data, and in drafting the manuscript. PF, SJ, CR and CS participated in the collection of data. AP and JN participated in the conception of the study, and in revising the manuscript. FA and AGC provided intellectual content of critical importance to the work described. All authors gave final approval of the version to be published.

\section{Author Details}

1Department of Nephrology and Renal Transplantation, Hospital de Santa Maria, Centro Hospitalar Lisboa Norte, EPE, Av. Prof. Egas Moniz, Lisboa, 1649035, Portugal and 2Department of Infectious Diseases, Hospital de Santa Maria, Centro Hospitalar Lisboa Norte, EPE, Av. Prof. Egas Moniz, Lisboa, 1649-035, Portugal

Received: 24 August 2009 Accepted: 2 June 2010

Published: 2 June 2010

\section{References}

1. Hoste EA, Clermont G, Kersten A, Venkataraman R, Angus DC, De Bacquer D, Kellum JA: RIFLE criteria for acute kidney injury are associated with hospital mortality in critically ill patients: a cohort analysis. Crit Care 2006, 10:R73.

2. Ostermann M, Chang RW: Acute kidney injury in the intensive care unit according to RIFLE. Crit Care Med 2007, 35:1837-1843.

3. Bagshaw SM, George C, Dinu I, Bellomo R: A multi-centre evaluation of the RIFLE criteria for early acute kidney injury in critically ill patients. Nephrol Dial Transplant 2008, 23:1203-1210.

4. Lopes JA, Fernandes P, Jorge S, Gonçalves S, Alvarez A, Costae Silva Z, França C, Martins Prata M: Acute kidney injury in intensive care unit patients: a comparison between the RIFLE and the Acute Kidney Injury Network classifications. Crit Care 2008, 12:R110.

5. Bagshaw SM, Laupland KB, Doig CJ, Mortis G, Fick GH, Mucenski M, Godinez-Luna T, Svenson LW, Rosenal T: Prognosis for long-term survival and renal recovery in critically ill patients with severe acute renal failure: A population based study. Crit Care 2005, 9:R700-R709.

6. Liaño F, Felipe C, Tenorio MT, Rivera M, Abraira V, Sáez-de-Urturi JM, Ocaña J, Fuentes C, Severiano S: Long-term outcome of acute tubular necrosis: A contribution to its natural history. Kidney Int 2007, 71:679-686.

7. Lins RL, Elseviers MM, Daelemans R: Severity scoring and mortality 1 year after acute renal failure. Nephrol Dial Transplant 2006, 21:1066-1068.

8. Neveu $H$, Kleinknecht $D$, Brivet $F$, Loirat $P$, Landais P: Prognostic factors in acute renal failure due to sepsis. Results of a prospective multicentre study. The French Study Group on Acute Renal Failure. Nephrol Dial Transplant 1996, 11:293-299.

9. Bagshaw SM, Uchino S, Bellomo R, Morimatsu H, Morgera S, Schetz M, Tan I, Bouman C, Macedo E, Gibney N, Tolwani A, Oudemans-van Straaten HM, Ronco C, Kellum JA, Beginning and Ending Supportive Therapy for the Kidney (BEST Kidney) Investigators: Septic acute kidney injury in critically ill patients: clinical characteristics and outcomes. Clin J Am SOC Nephrol 2007, 2:431-439.

10. Hoste EA, Lameire NH, Vanholder RC, Benoit DD, Decruyenaere JM, Colardyn FA: Acute renal failure in patients with sepsis in a surgical ICU: predictive factors, incidence, comorbidity, and outcome. J Am SoC Nephrol 2003, 14:1022-1030.

11. Oppert $M$, Engel $C$, Brunkhorst FM, Bogatsch $H$, Reinhart $K$, Frei U, Eckardt KU, Loeffler M, John S, German Competence Network Sepsis (Sepnet): Acute renal failure in patients with severe sepsis and septic shock a 
significant independent risk factor for mortality: results from the German Prevalence Study. Nephrol Dial Transplant 2008, 23:904-909.

12. Bagshaw SM, George C, Bellomo R, ANZICS Database Management Committee: Early acute kidney injury and sepsis: a multicentre evaluation. Crit Care 2008, 12:R47.

13. Chen YC, Jenq CC, Tian YC, Chang MY, Lin CY, Chang CC, Lin HC, Fang JT, Yang CW, Lin SM: Rifle classification for predicting in-hospital mortality in critically ill sepsis patients. Shock 2009, 31:139-145.

14. Lopes JA, Jorge S, Resina C, Santos C, Pereira A, Neves J, Antunes F, Prata MM: Acute kidney injury in patients with sepsis: a contemporary analysis. Int J Infect Dis 2009, 13:176-181.

15. Bellomo R, Ronco C, Kellum JA, Mehta RL, Palevsky P, Acute Dialysis Quality Initiative workgroup: Acute renal failure - definition, outcome measures, animal models, fluid therapy and information technology needs: the Second International Consensus Conference of the Acute Dialysis Quality Initiative (ADQI) Group. Crit Care 2004, 8:R204-R212.

16. Manjunath G, Sarnak MJ, Levey AS: Prediction equations to estimate glomerular filtration rate: an update. Curr Opin Nephrol Hypertens 2001, 10:785-792.

17. Levy MM, Fink MP, Marshall JC, Abraham E, Angus D, Cook D, Cohen J, Opal SM, Vincent JL, Ramsay G, SCCM/ESICM/ACCP/ATS/SIS: 2001 SCCM/ ESICM/ACCP/ATS/SIS International Sepsis Definitions Conference. Crit Care Med 2003, 4:1250-1256.

18. Knaus WA, Draper EA, Wagner DP, Zimmerman JE: APACHE II: a severity of disease classification system. Crit Care Med 1985, 13:818-829.

19. Coca SG, Yusuf B, Shlipak MG, Garg AX, Parikh CR: Long-term risk of mortality and other adverse outcomes after acute kidney injury: a systematic review and meta-analysis. Am J Kidney Dis 2009, 6:961-973.

20. Basile DP, Donohoe $D$, Roethe $K$, Osborn JL: Renal ischemic injury results in permanent damage to peritubular capillaries and influences longterm function. Am J Physiol Renal Physiol 2001, 281:F887-F899.

21. Basile DP: Rarefaction of peritubular capillaries following ischemic acute renal failure: a potential factor predisposing to progressive nephropathy. Curr Opin Nephrol Hypertens 2004, 13:1-7.

22. Burne-Taney MJ, Liu M, Ascon D, Molls RR, Racusen L, Rabb H: Transfer of lymphocytes from mice with renal ischemia can induce albuminuria in naïve mice: a possible mechanism linking early injury and progressive renal disease? Am J Physiol Renal Physiol 2006, 291:F981-F986.

23. Tonelli M, Wiebe N, Culleton B, House A, Rabbat C, Fok M, McAlister F, Garg AX: Chronic kidney disease and mortality risk: a systematic review. J Am Soc Nephrol 2006, 17:2034-2047.

24. Levy EM, Viscoli CM, Horwitz RI: The effect of acute renal failure on mortality. A cohort analysis. JAMA 1996, 275:1489-1494.

25. Kelly KJ: Distant effects of experimental renal ischemia/reperfusion injury. J Am Soc Nephrol 2003, 14:1549-1558.

26. Hassoun HT, Lie ML, Grigoryev DN, Liu M, Tuder RM, Rabb H: Kidney ischemia-reperfusion injury induces caspase-dependent pulmonary fibrosis. Am J Physiol Renal Physiol 2009, 1:F125-137.

27. Bagshaw SM, Uchino S, Cruz D, Bellomo R, Morimatsu H, Morgera S, Schetz M, Tan I, Bouman C, Macedo E, Gibney N, Tolwani A, Oudemansvan Straaten HM, Ronco C, Kellum JA, for the Beginning and Ending Supportive Therapy for the Kidney (BEST Kidney) Investigators: A comparison of observed versus estimated baseline creatinine for determination of RIFLE class in patients with acute kidney injury. Nephrol Dial Transplant 2009, 24:2739-2744.

28. Bellomo R, Wan L, Langenberg C, May C: Septic acute kidney injury: new concepts. Nephron Exp Nephrol 2008, 109:e95-100.

29. Dellinger RP, Levy MM, Carlet JM, Bion J, Parker MM, Jaeschke R, Reinhart K, Angus DC, Brun-Buisson C, Beale R, Calandra T, Dhainaut JF, Gerlach H, Harvey M, Marini JJ, Marshall J, Ranieri M, Ramsay G, Sevransky J, Thompson BT, Townsend S, Vender JS, Zimmerman JL, Vincent JL, International Surviving Sepsis Campaign Guidelines Committee; American Association of Critical-Care Nurses; American College of Chest Physicians: Surviving Sepsis Campaign international guidelines for management of severe sepsis and septic shock: 2008. Crit Care Med 2008, 36:296-327.

Pre-publication history

The pre-publication history for this paper can be accessed here: http://www.biomedcentral.com/1471-2369/11/9/prepub doi: 10.1186/1471-2369-11-9

Cite this article as: Lopes et al., Long-term risk of mortality after acute kidney injury in patients with sepsis: a contemporary analysis BMC Nephrology 2010, 11:9

\section{Submit your next manuscript to BioMed Central} and take full advantage of:

- Convenient online submission

- Thorough peer review

- No space constraints or color figure charges

- Immediate publication on acceptance

- Inclusion in PubMed, CAS, Scopus and Google Scholar

- Research which is freely available for redistribution

Submit your manuscript at www.biomedcentral.com/submit
C BioMed Central 